Albetris

\title{
Kontribusi Sektor Pertanian dan Pengaruhnya Terhadap Perekonomian Daerah Provinsi Jambi
}

\author{
Albetris \\ Dosen Fakultas Ekonomi Universitas Batanghari Jambi \\ Correspondence email: albetris90@gmail.com
}

\begin{abstract}
The purpose of this research is to find out and analyze the large contribution of the agricultural sector to the economy of the regional province of Jambi and influence the agricultural sector against economic growth the province of Jambi. The object of the research is done in the agricultural sector, economic growth and GDP Jambi province. The data used in this research is the secondary data, this research are deskriptive quantitative, quantitative formulation can answer twist of the problem. The first results showed a contribution of the agricultural sector to the total GDP Jambi province for 13 years (in 2006 - the year 2018) that ranges from $25.12 \%$ to $27.44 \%$, the greatest contribution took place in 2008, namely of 27.44\%. Meanwhile, the contribution of the agricultural sector to the total GDP the lowest occurred in the year 2015, namely of 25.12\%. the median contribution in sub sectors of the fishery towards the agricultural sector amounted to 26.19\%. and the second results of the estimation of simple regression model shows a positive regression coefficient i.e. $Y=1.033+0340 \mathrm{X}$. This showing that the higher growth in the agricultural sector, it will spur economic growth in the province of Jambi 2005-2017 with the R-square of 99.10\% with a confidence level significance alfa $=5 \%$, that influence the agricultural sector very convincing. And $0.90 \%$ influenced by other factors.
\end{abstract}

Keywords: Contribution of Agricultural Sector, Gross Domestic Regional Product, The Economic of Jambi Province,

\section{PENDAHULUAN}

Tujuan dari kebijakan pembangunan daerah adalah seluas-luasnya untuk meningkatkan kesejahteraan masyarakat, ditandai dengan adanya perkembangan ekonomi antar pertumbuhan ekonomi. Suatu perekonomian daerah dikatakan mengalami pertumbuhan atau perkembangan apabila tingkat kegiatan ekonomi suatu masyarakat tersebut lebih tinggi dari kegiatan ekonomi yang di capai pada masa sebelumnya, atau dengan kata lain terjadinya kenaikan produk domestic bruto secara rill. Sektor pertanian sebagai salah satu sektor perekonomian termasuk sektor yang sangat potensial dalam memberikan sumbangan terhadap pertumbuhan dan pembangunan ekonomi daerah, baik dari segi pendapatan maupun penyerapan tenaga kerja. Disamping itu, usaha dalam sektor pertanian akan selalu berjalan selama manusia masih memerlukan hasil pertanian untuk mempertahankan hidup dan manusia masih memerlukan hasil pertanian sebagai bahan baku dalam industrinya. Sektor pertanian terdiri dari subsektor tanaman bahan makanan, subsektor perkebunan, subsektor perikanan, subsektor peternakan dan subsektor kehutanan.

Provinsi Jambi merupakan salah satu daerah yang struktur ekonominya masih bercorak Agraris, dimana sebagian besar kegaitan ekonominya masih bertumpu pada sektor pertanian. Ini menunjukkan bahwa perekonomian Provinsi masih di dukung penuh oleh sektor pertanian, yang terlihat dari besarnya kontribusi sektor pertanian terhadap PDRB. Pertumbuhan PDRB tidak lepas dari peran setiap sektor ekonomi tersebut diatas dan keterkaitannya antar sektor yang satu dengan lainnya. Besar kecilnya kontribusi pendapatan setiap sektor ekonomi merupakan hasil perencanaan serta pembangunan sektoral yang dilaksanakan di daerah. Keberhasilan pembangunan daerah sangat ditentukan oleh keberhasilan dalam melaksanakan strategi perencanaan pembangunan daerah dengan mengoptimalkan semua potensi dan sumberdaya, hal ini mutlak dilakukan dalam era otonomi daerah, dengan mengedepankan kemandirian dan peran aktif pemerintah daerah serta pemberdayaan masyarakat dan swasta. Berdasarkan teori basis ekonomi, faktor penentu pertumbuhan ekonomi suatu daerah adalah berhubungan langsung dengan permintaan akan barang dan jasa dari luar dearah 9 (Arsyad, 2009). Pertumbuhan industri yang menggunakan sumberdaya lokal, termasuk tenaga kerja dan bahan baku untuk di ekspor akan menghasilkan kekayaan daerah dan menciptakan peluang kerja (job creation).

Kekuatan ekonomi yang memadai tentu menimbulkan pengaruh yang tersebar ke berbagai sektor non unggulan. Pendapatan sektor unggulan tersebut dapat mempengaruhi kesempatan kerja dalam daerah tidak hanya dalam sektor yang diandalkan tersebut, tetapi juga pada sektor-sektor yang lain sebagai imbas 
keberhasilan pambangunan sektor unggulan. Pembangunan ekonomi di Provinsi Jambi memperlihatkan trend yang positif. Perubahan kontribusi sektor dalam PDRB Provinsi Jambi dapat dilihat pada tabel berikut:

Tabel 1

Perkembangan Sektor Ekonomi Provinsi Jambi Tahun 2013 - 2017

\begin{tabular}{|c|c|c|c|c|c|c|}
\hline Sektor & 2013 & 2014 & 2015 & 2016 & 2017 & Rata-rata \\
\hline Pertanian, Kehutanan, dan Perikanan & 4.73 & 6.81 & 6.21 & 10.95 & 5.63 & 6.81 \\
\hline Pertambangan dan Penggalian & 12.41 & 4.88 & 3.83 & 4.23 & -0.22 & 5.03 \\
\hline Industry Pengolahan & 8.3 & 7.19 & 8.17 & 4.81 & 2.33 & 6.16 \\
\hline Pengadaan Listrik dan Gas & 13.32 & 9.67 & 8.73 & 9.7 & 4.18 & 9.12 \\
\hline \multicolumn{7}{|c|}{ Pengadaan Air, Pengelolaan Sampah, Limbah dan } \\
\hline Daur Ulang & 5.21 & 0.82 & 1.87 & 4.35 & 4.08 & 3.27 \\
\hline Konstruksi & 5.52 & 17.02 & 19.49 & 8.94 & 2.88 & 10.77 \\
\hline \multicolumn{7}{|c|}{ Perdagangan Besar dan Eceran, Reparasi Mobil, dan } \\
\hline Sepeda Motor & 8.34 & 8.86 & 8.22 & 8.8 & 11.02 & 9.05 \\
\hline Transportasi dan Pergudangan & 5.81 & 8.42 & 7.88 & 8.18 & 6.59 & 7.37 \\
\hline Penyediaan Akomodasi dan Makan Minum & 6.24 & 7.73 & 6.4 & 18.73 & 6.49 & 9.12 \\
\hline Informasi dan Komunikasi & 7.32 & 7.36 & 6.53 & 7.01 & 9.83 & 7.61 \\
\hline Jasa Keuangan dan Asuransi & 20.79 & 9.98 & 11.81 & 3.84 & 2.11 & 9.71 \\
\hline Real Estate & 6.05 & 5.66 & 4.93 & 2.2 & 4.19 & 4.61 \\
\hline Jasa Perusahaan & 1.49 & 4.22 & 2.04 & 5 & 6.32 & 3.81 \\
\hline \multicolumn{7}{|l|}{ Administrasi Permerintahaan, Pertanahan dan } \\
\hline Jaminan Sosial Wajib & 4.14 & 3.96 & 4.57 & 13.38 & 6.79 & 6.57 \\
\hline Jasa Pendidikan & 2.48 & 6.34 & 5.39 & 1.28 & 7.48 & 4.6 \\
\hline Jasa Kesehatan dan Kegiatan Sosial & 3.8 & 8.78 & 8.07 & 15.19 & 10.05 & 9.18 \\
\hline Jasa Lainnya & 3.8 & 3.31 & 4.8 & 5.55 & 8.76 & 5.24 \\
\hline PDRB & 7.86 & 7.03 & 6.84 & 7.35 & 4.21 & 6.66 \\
\hline
\end{tabular}

Sumber : BPS Provinsi Jambi, data diolah

Terlihat perkembangan dari tiap-tiap sektor ekonomi yang memberikan kontribusi terhadap PDRB Provinsi Jambi. Laju pertumbuhan ekonomi Provinsi Jambi periode 2013-2017 cukup tinggi dengan ratarata 6.66 persen pertahun, namun peningkatan pertumbuhan ekonomi ini masih di dominasi sektor primer yaitu sektor pertanian. Tujuan Penelitian ini adalah menganalisis besarnya kontribusi sektor pertanian terhadap PDRB Provinsi Jambi.

\section{Kerangka Pemikiran}

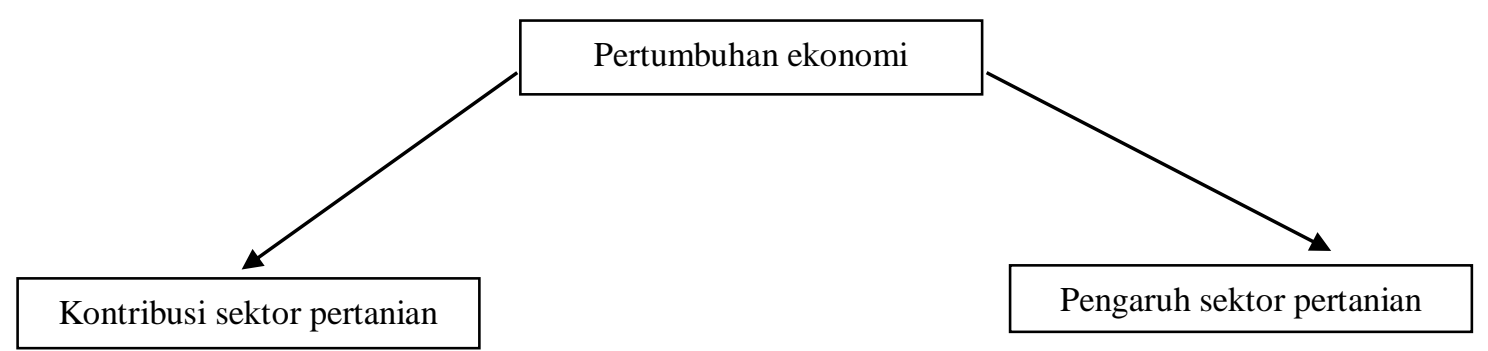

\section{Gambar 1 \\ Kerangka Pemikiran}

Aktivitas suatu sektor perekonomian tidak terlepas dengan sektor-sektor perekonomian yang lain, sehingga suatu kebijakan yang berkaitan langsung dengan sektor tersebut akan berimbas pada perekonomian secara makro. Peranan sektor-sektor perekonomian pada hakekatnya merupakan penggambaran dari adanya saling keterkaitan diantara sektor-sektor perekonomian tersebut, yang keterkaitannya perlu di analisis lebih lanjut terhadap sektor-sektor lainnya. Keseimbangan secara umum seluruh sektor dalam perekonomian adalah satu kesatuan sistem, dengan keseimbangan (atau ketidakseimbangan) di satu sektor berpengaruh terhadap keseimbangan atau ketidaksimbangan di sektor lain. Analisis digunakan untuk mengetahui 
pengaruhnya dan kontribusi sektor-sektor pertanian sehingga pada akhirnya dapat dilakukan subsektor mana yang merupakan sektor kunci (key sector) pada sektor pertanian dalam peningkatan PDRB Provinsi Jambi

Hipotesis

Berdasarkan perumusan masalah dan kerangka pemikiran yang dikembangkan dapat dirumuskan hipotesis, yaitu : diduga sektor pertanian mempunyai pengaruh yang positif dan signifikan terhadap pertumbuhan ekonomi di Provinsi Jambi

\section{METODE PENELITIAN}

Metode yang digunakan dalam penelitian ini adalah metode analisis data sekunder. Data sekunder diperoleh dari instansi terkait dan kemudian data tersebut di jelaskan secara deskriptif kuantitatif dan kualitatif. Dalam penelitian ini juga dilakukan dengan penelitian kepustakaan (liblary research), ini dilakukan dengan menggunakan buku dan referensi lainnya sejenis atau berkaitan dengan penelitian ini yang sudah di lakukan sebelumnya. Cara ini dilakukan untuk memperkuat teori dan mendukung studi yang bersifat komperatif analisis.

\section{Jenis dan Sumber Data}

Data yang dikumpulkan dalam penelitian ini adalah data sekunder yang disajikan dalam bentuk data tahunan/series, mulai dari tahun 2006 -2018, adapun data yang dikumpulkan adalah : PDRB Provinsi Jambi menurut lapangan usaha; pertumbuhan ekonomi Provinsi Jambi; dan Sektor pertanian. Data yang digunakan dalam penelitian ini adalah yang diperoleh dari berbagai instansi terkait, antara lain dari BPS Provinsi Jambi.

\section{Metode Analisis}

Adapun model analisis yang digunakan untuk pengujian hipotesis dalam penelitian ini adalah :

1. Kajian ini menjawab permasalahan pertama mengetahui seberapa besar kontribusi sektor pertanian terhadap PDRB Provinsi Jambi. Kontribusi tersebut dapat dihitung dengan rumus: $K s p=\frac{\text { PDRBsp } t}{\text { PDRBt }} X 100 \%$

Dimana: Ksp : kontribusi sektor pertanian (persen); PDRB : produk domestic regional bruto (juta rupiah); PDRB sp : produk domestic regional bruto sektor pertanian (juta rupiah); $\mathrm{t}$ : waktu

2. Kajian permasalahan kedua adalah untuk mengetahui seberapa besar pengaruh variabel sektor pertanian (X) terhadap pertumbuhan ekonomi (Y) di Provinsi Jambi. Variabel tersebut dapat dihitung dengan regresi linier sederhana dengan rumus formulanya, yaitu :

\section{$\mathrm{Y}=\mathrm{a}+\beta \mathrm{X}+\mathrm{e}$}

Keterangan : Y : pertumbuhan ekonomi; $\mathrm{X}$ untuk sektor pertanian; e : standart error

\section{Uji Hipotesis \\ Uji Signifikan Parameter Individual ( Uji Statistik t)}

uji t dilakukan untuk melihat signifikansi dari pengaruh variabel bebas secara individual terhadap variabel terikat dengan menganggap variabel bebas lainnya adalah konstan. Pada tingkat signifikansi 5 persen dengan pengujian yang digunakan adalah sebagai berikut : $\mathrm{H}_{0}$ ditolak $\mathrm{H}_{1}$ diterima apabila $\mathrm{t}$ hitung $>\mathrm{t}$ tabel, yang berarti variabel independennya berpengaruh secara signifikan terhadap variabel dependen. Pengambilan keputusan dalam melakukan pengujian hipotesis dengan pendekatan uji $\mathrm{t}$ adalah dengan membandingkan antara nilai thitung terhadap nilai t tabel, dengan keputusan sebagai berikut :

1. Jika $\mathrm{t}$ hitung $>\mathrm{t}$ tabel, maka menolak $\mathrm{H}_{0}$ (tidak ada hubungan/pengaruh anatra variebel bebas dengan variabel tidak bebas) dan menerima $\mathrm{H}_{\mathrm{a}}$ (ada hubungan/pengaruh antara variabel bebas dengan variabel tidak bebas).

2. Jika $t$ hitung $<\mathrm{t}$ tabel, maka menolak $\mathrm{H}_{\mathrm{a}}$ (ada hubungan/pengaruh antara variebel bebas dengan variabel tidak bebas) dan menerima $\mathrm{H}_{0}$ (tidak ada hubungan/pengaruh antara variabel bebas dengan variabel tidak bebas). 


\section{Koefisien determinasi $\left(R^{2}\right)$}

Koefisien determinasi $\left(\mathrm{R}^{2}\right)$ pada intinya mengukur seberapa jauh kemampuan model. Dalam menerangkan variabel independen. Nilai koefisien determinasi diantara 0 dan $1\left(0<R^{2}<1\right)$, nilai $\left(R^{2}\right)$ yang kecil berarti kemampuan variabel-variabel independen dalamm menjelaskan variasi variabel independen sangat terbatas. Nilai yang mendekati 1 berarti variabel memberikan hampir semua informasi yang dibutuhkan untuk memperoleh prediksi variasi model dependen. Semakin tinggi nilai keofisien determinasi maka akan semakin baik pula kemampuan variabel independen dalam menjelaskan variabel dependen. (Zahari, 2017)

\section{Operasional variabel}

Untuk menunjang pembahasan dan pengkajian lebih lanjut topik yang akan diteliti perlu dikemukakan beberapa definisi operasional variabel. Yaitu :

1. Produk domestic regional bruto (PDRB)

PDRB pada dasarnya merupakan jumlah nilai tambah yang dihasilkan oleh seluruh unit usaha dalam suatu wilayah Regional (Provinsi/Kabupaten/Kota) tertentu, atau merupakan jumlah nilai barang dan jasa akhir yang dihasilkan oleh seluruh unit ekonomi.

2. Pertumbuhan ekonomi

Pertumbuhan ekonomi adalah naiknya pendapatan PDRB dari tahun ketahun yang diukur dalam harga konstan dalam persentase di suatu daerah

Total dari sub sektor pertanian, sub sektor perkebunan, sub sektor tanaman bahan makanan, sub sektor kehutanan, dan sub sektor peternakan yang dikumpulkan selama kurun waktu lima tahun yang diukur dalam satuan rupiah.

\section{HASIL DAN PEMBAHASAN}

\section{Kontribusi Sektor Pertanian Terhadap Total PDRB Provinsi Jambi}

Potensi sektor pertanian di Provinsi Jambi sangat besar. Sebagian besar wilayah Provinsi Jambi adalah lahan dengan kultur pertanian dalam bentuk perkebunan, sehingga sangatlah wajar bila sektor pertanian berkembang cukup pesat di Provinsi Jambi, bahkan menjadi penyumbang cukup besar dalam struktur perekonomian di Provinsi Jambi. Hal ini dibuktikan dengan besarnya sumbangan sektor pertanian terhadap perekonomian Provinsi Jambi yang mampu mencapai rata-rata $26.19 \%$ pertahun, periode tahun 2006 - 2018. Artinya aktivitas ekonomi di Provinsi Jambi di sumbang oleh sektor pertanian sebesar 26.19\% yang berarti selama periode 2006 - 2018 PDRB sektor pertanian Provinsi Jambi selalu mengalami peningkatan dari tahun ke tahun sehingga perlu kiranya mendapat perhatian untuk meningkatkan sektor pertanian dalam bentuk pengelolaan yang lebih memadai agar dapat di peroleh hasil yang lebih optimal. Adapun kontribusi sektor pertanian di Provinsi Jambi terhadap PDRB total adalah sebagai berikut :

Tabel 2

Kontibusi PDRB Sektor Pertanian Terhadap Total PDRB Provinsi Jambi Periode 2006 - 2018

\begin{tabular}{crrr}
\hline Tahun & $\begin{array}{c}\text { PDRB ADHK 2010 Sektor Pertanian } \\
\text { (Rp. Juta) }\end{array}$ & $\begin{array}{c}\text { Total PDRB ADHK 2010 Sektor } \\
\text { Pertanian (Rp. Juta) }\end{array}$ & Kontribusi (\%) \\
\hline 2006 & $16,329,498$ & $62,003,525$ & $26.34 \%$ \\
2007 & $17,081,731$ & $65,458,452$ & $26.10 \%$ \\
2008 & $19,018,092$ & $69,315,670$ & $27.44 \%$ \\
2009 & $19,886,784$ & $74,043,736$ & $26.86 \%$ \\
2010 & $21,023,977$ & $79,254,535$ & $26.53 \%$ \\
2011 & $22,384,477$ & $84,416,204$ & $26.52 \%$ \\
2012 & $23,627,242$ & $90,618,411$ & $26.07 \%$ \\
2013 & $24,744,879$ & $97,740,874$ & $25.32 \%$ \\
2014 & $26,429,045$ & $104,615,082$ & $25.26 \%$ \\
2015 & $28,070,963$ & $111,766,131$ & $25.12 \%$ \\
2016 & $31,145,429$ & $119,991,445$ & $25.96 \%$ \\
2017 & $32,815,888$ & $125,037,398$ & $26.24 \%$ \\
2018 & $34,933,689$ & $130,501,132$ & $26.77 \%$ \\
Rata-rata & $24,422,438$ & $93,443,277$ & \\
\hline Surne. & & $26.19 \%$ \\
\hline
\end{tabular}

Sumber : BPS Provinsi Jambi, data diolah 
Tabel 2 diatas juga menggambarkan kontribusi sektor pertanian terhadap total PDRB Provinsi Jambi, dimana selama tahun 2006 - 2018 sumbangan sektor pertanian terhadap total PDRB Provinsi Jambi menunjukkan kecenderungan meningkat secara berfluktuasi besar sumbangsi secara rata-ratanya kurang dari $30 \%$ dimana sumbangan sektor pertanian terhadap total PDRB Provinsi Jambi tertinggi terjadi pada tahun 2008, yaitu sebesar $27,44 \%$. Tingginya sumbangan sektor pertanian pada tahun tersebut disebabkan karena sektor pertanian merupakan sektor potensial yang mana lahan yang digunakan tersedia denagn luas yang juga diikuti semakin meningkatnya kegiatan di sektor pertanian yang tergambar dari meningkatnya PDRB di tahun tersebut. Sedangkan kontribusi sektor pertanian paling rendah terhadap total PDRB Provinsi Jambi terjadi pada tahun 2015, yaitu sebesar 25,12\%. Rendahnya kontribusi tahun 2015 lebih disebabkan oleh lemahnya permintaan atas komoditi sektor pertanian Provinsi Jambi, akibat daya beli masyarakat yang rendah yang dikarenakan terjadi kelesuan ekonomi serta pertumbuhan sektor pertanian di tahun tersebut yang hanya tumbuh sebesar 6,21\% turun dibandingkan dengan tahun sebelumnya, sementara sektor lainnya menunjukkan kecendrungan yang meningkat.

\section{Pengaruh Sektor Pertanian Terhadap Pertumbuhan Ekonomi}

Menjawab perumusan masalah yang kedua digunakan dalam pengujian model kuantitatif dalam penelitian ini adalah dengan menggunakan metode regresi linier sederhana, dengan menggunakan program spss, dimana hasil yang didapat :

Tabel 3

Estimasi model regresi linier sederhana

\begin{tabular}{|rl|r|r|r|r|r|}
\hline \multirow{2}{*}{ Model } & \multicolumn{2}{|l|}{ Unstandardized Coefficients } & Standardized Coefficients & \multirow{2}{*}{$\mathrm{t}$} & \multirow{2}{*}{ Sig. } \\
\cline { 3 - 7 } & (Constant) & $\mathrm{B}$ & Std. Error & Beta & & \\
\hline \multirow{2}{*}{1} & $\mathrm{X}$ & .340 & .223 & & 1.526 & .155 \\
& & 1.033 & .030 & -.995 & 34.236 & .000 \\
\hline
\end{tabular}

Sumber: data olahan

$\mathrm{Y}=0.340+1.033 \mathrm{X}$

Hasil persamaan regresi diatas secara keseluruhan bahwa nilai koefisien $\beta_{0}$ sebesar 1.033 artinya, apabila selama tahun 2006 sampai 2018 tidak terjadi perubahan variabel sektor pertanian (X) tidak mengalami perubahan atau dengan asumsi konstan, maka pertumbuhan ekonomi (Y) untuk Provinsi Jambi akan tetap sebesar 0.340 persen. Untuk koefisien regresi variabel $X(\beta)$ diperoleh sebesar 1.033, artinya apabila terjadi kenaikan atau peningkatan sektor pertanian $(\mathrm{X})$ sebesar 1 persen, maka akan menaikkan pertumbuhan ekonomi (Y) untuk Provinsi Jambi sebesar 1.033 persen dengan asumsi bahwa variabel lain tetap (cateris paribus) atau tidak terjadi perubahan atau konstan. Hasil regresi untuk koefisien sektor pertanian tersebut, menggambarkan bahwa kondisi dan pengaruh sektor pertanian terhadap peningkatan perumbuhan ekonomi Provinsi Jambi masih rendah, jauh dari harapan. Hal ini dikarenakan belum optimalnya pemanfaatan potensi SDA yang dimiliki terutama hasil dari sektor pertanian dan menjadi perhatian pemerintah daerah kedepannya untuk segera mengambil kebijakan yang tepat dan efektif agar sektor pertanian berpengaruh besar terhadap peningkatan pertumbuhan ekonomi Provinsi Jambi.

\section{Uji Individu Atau Uji Parsial Dengan Menggunakan Uji - $t$}

Berdasarkan uji statistik parsial dengan tingkat keyakinan $a=5 \%$, diperoleh nilai statistik untuk variabel $\mathrm{X}(\beta)$ yang nilainya lebih besar dari t-prob ( $34.236>0.05$ ), artinya $\mathrm{H}_{0}$ ditolak $\mathrm{H}_{1}$ diterima. Hal ini menunjukkan bahwa sektor pertanian (X) selama periode 2006 sampai dengan 2018 berpengaruh signifikan terhadap pertumbuhan ekonomi (Y) di Provinsi Jambi pada tingkat keyakinan a dibawah 5 persen. Dalam hal ini sektor pertanian memiliki potensi yang cukup besar dalam meningkatkan pertumbuhan ekonomi Provinsi Jambi. 
Tabel 4

Uji tingkat signifikansi dengan menggunakan R- squared $\left(\mathbf{R}^{\mathbf{2}}\right)$

\begin{tabular}{|l|l|l|l|l|}
\hline Model & R & R Square & Adjusted R Square & Std. Error of the Estimate \\
\hline 1 & $.995^{\mathrm{a}}$ & .991 & .990 & .01109 \\
\hline
\end{tabular}

Sumber: data olahan

Hasil perhitungan $\mathrm{R}$ - squared yang ditunjukkan pada persamaan diatas diperoleh nilai $\mathrm{R}^{2}$ sebesar 0.991 mendekati $\mathrm{I}\left(0<\mathrm{R}^{2}<1\right)$. Artinya semakin besar hubungan antara kedua variabel tersebut, menunjukkan bahwa sekitar $99.10 \%$ naiknya pertumbuhan ekonomi (Y) di Provinsi Jambi di pengaruhi oleh variabel sektor pertanian $(\mathrm{X})$ sedangkan sisanya $0.90 \%$. dijelaskan oleh variabel lain yang tidak dimasukkan kedalam persamaan regresi.

\section{SIMPULAN}

Berdasarkan hasil penelitian dan pembahasan maka dapat disimpulkan beberapa hal sebagai berikut :

1. Kontribusi sektor pertanian terhadap total PDRB Provinsi Jambi Selama 13 tahun (tahun 2006 - tahun 2018) yaitu berkisar antara $25,12 \%$ hingga $27,44 \%$, kontribusi yang paling besar terjadi pada tahun 2008 yaitu sebesar $27,44 \%$. Sementara itu kontribusi sektor pertanian terhadap total PDRB yang paling rendah terjadi pada tahun 2015 yaitu sebesar 25,12\%. Rata-rata kontribusi sub sektor perikanan terhadap sektor pertanian sebesar 26,19\%.

2. Hasil estimasi model regresi linier sederhana memperlihatkan koefisien regresi yang positif yaitu $\mathrm{Y}=$ $0.340+1.033 \mathrm{X}$. Hal ini memperlihatkan, bahwa semakin tinggi pertumbuhan sektor pertanian maka akan memacu pertumbuhan ekonomi Provinsi Jambi 2006 -2018 dengan R-square yaitu sebesar 99,10\% dengan tingkat keyakinan $a=5 \%$, bahwa tingkat signifikansi pengaruh sektor pertanian sangat meyakinkan. dan $0.90 \%$ dipengaruhi oleh faktor-faktor lainnya.

\section{DAFTAR PUSTAKA}

Anonym. 2016. Badan Pusat Statistik. Data dan Informasi Kemiskinan Tahun 2010 - 2015, BPS, Jakarta

Adisetiawan, R., 2012. Analisis Pengaruh Kinerja Keuangan dalam Memprediksi Pertumbuhan Laba, Jurnal Aplikasi Manajemen, 10(3), 669-681

Adisetiawan, R., and Surono, Yunan, 2016. Earnings Management and Accounting Information Value:

Impact and Relavance, Business, Management and Economics Research, 2(10), 170-179

Adisetiawan, R., dan Surono, Yunan., 2011, Analisa Pengaruh Variabel-variabel Fundamental Terhadap

Return Saham LQ45, Jurnal Ilmiah Universitas Batanghari Jambi, 11(2), 21-31

Arsyad, Lincolin, 2009, Ekonomi Pembangunan, Edisi Ketiga, FEUGM, Penerbit STIE YKPN, Yogyakarta

Stevens et al. 2000. Theory Of Rice Consumption. Harper and Row Publisher, Inc. Great Britain.

Suryana.A dan Mardianto Krisnamurti. 2001. Bunga Rampai Ekonomi Beras. Jakarta : Fakultas Ekonomi, Universitas Indonesia.

Zahari, M., 2017, Pengaruh Pengeluaran Pemerintah Terhadap Pertumbuhan Ekonomi di Provinsi Jambi, Ekonomis, Journal of Economics and Business, 1(1), 180-196 